\title{
Hypoglycemic and hypolipidemic effects of different parts and formulations of bitter gourd (Momordica Charantia)
}

\author{
Mahwish, Farhan Saeed, Muhammad Sajid Arshad*, Mahr un Nisa, Muhammad Tahir Nadeem \\ and Muhammad Umair Arshad
}

\begin{abstract}
Background: Cardiovascular diseases and diabetes are responsible for large number of deaths throughout the globe. Bitter gourd has the potential to become a component of the diet or a dietary supplement for diabetic and pre-diabetic patients owing to the presence of insulin like molecules. Recent investigations have suggested that bitter gourd extracts may ameliorate high fat diet induced obesity and hyperlipidemia in animal models. Moreover, its supplements in food result in lowering weight gain and visceral fat mass.
\end{abstract}

Methods: The current study was designed to investigate the nutraceutical potential of skin, flesh and whole fruit of bitter gourd cultivars against hyperglycemia and hyperlipidemia. For the purpose, various bitter gourd cultivars were procured from local market. Bio-evaluation studies were carried out on biochemical parameters using rodent experiment model.

Results: From results, it was revealed that maximum reduction in blood glucose skin $1.06 \%$, flesh $2.65 \%$, whole fruit 4.29\%, total cholesterol skin 6.60\%, flesh 6.04\%, whole fruit 6.70\%, low density lipoprotein skin 5.55\%, flesh 6.81\%, whole fruit $6.60 \%$, and triglycerides skin $0.04 \%$, flesh $3.38 \%$, whole fruit $2.02 \%$, were observed. Moreover, insulin skin $2.14 \%$, flesh $3.52 \%$, whole fruit $2.73 \%$, production was slightly enhanced with improved levels of high density lipoprotein in whole fruit of bitter gourd.

Conclusion: Overwhelmingly, it may be inferred here that bitter gourd holds the potential to significantly improve diabetic conditions and associated late complications with no ill effects on body organs.

Keywords: Functional foods, Bitter gourd, Nutraceutical, Hyperglycemia, Hyperlipidemia

\section{Background}

Incidence of chronic diseases is a rising apprehension globally with ever escalating reported cases of physiological syndromes. Besides, continued oxidative stress and oxidative damage lead to chronic inflammation and other physiological abnormalities [1]. Among these chronic diseases, diabetes and cardiovascular (CVD) are responsible for large number of deaths in the world [2]. Diabetes mellitus is an emerging global health perspective that is prevalent in more than 285 million people worldwide. It has been anticipated that diabetes affected people will be around 439 million by 2030 . Furthermore,

\footnotetext{
* Correspondence: sajid_ft@yahoo.com; msajidarshad@gcuf.edu.pk Institute of Home \& Food Sciences, Government College University, Faisalabad 38040, Pakistan
}

(c) The Author(s). 2017 Open Access This article is distributed under the terms of the Creative Commons Attribution 4.0 International License (http://creativecommons.org/licenses/by/4.0/), which permits unrestricted use, distribution, and reproduction in any medium, provided you give appropriate credit to the original author(s) and the source, provide a link to the Creative Commons license, and indicate if changes were made. The Creative Commons Public Domain Dedication waiver (http://creativecommons.org/publicdomain/zero/1.0/) applies to the data made available in this article, unless otherwise stated.

it has been projected that about $75 \%$ of the affected people will be from developing countries [3]. As far as the hyperlipidemia is concerned, it is lipid metabolism disorder and major risk factor for the development of cardiovascular aberration. It is prevalent among $7 \%$ of the adult population with an estimated 25 million people affected $[4,5]$.

Diabetes mellitus treatment often results in some late complex abnormalities including nephropathy, neuropathy and retinopathy etc. Due to adverse responses and rely upon low cost therapeutic ways, about 30\% of diabetic patients use alternative therapeutic ways [6]. Various plant based remedial strategies are being utilized worldwide to cope with the chronic diseases and infections as preventive and curative measure. According to 
the statistics of WHO plant based medicines are being used by nearly $80 \%$ of the people for their primary healthcare worldwide. This analeptic potential of plant based medication is ratified to an array of valued phytochemicals present predominantly in their waste products. Among these, bitter gourd and its various components and formulations can be used due to their sugar lowering effects via biochemical, pharmacological and physiological modes [7, 8].

Bitter gourd (Momordica charantia L.) is a climbing perennial, tendril-bearing vine belongs to family cucurbitaceae. In the past, it was frequently used as antidote for diabetes, stomach pain, wounds, tumors, malaria, rheumatism, colic, inflammation, measles and fevers $[9,10]$. Owing to the presence of insulin like molecules, bitter gourd has the potential to become a component of the diet or a dietary supplement for diabetic and pre-diabetic patients [11]. Recently, many researchers evaluated the role of bitter gourd in lowering blood glucose level [12, 13], cholesterol [13, 14] and visceral fat mass [15].

Recent researches also suggested that bitter gourd extracts may ameliorate high fat diet induced obesity and hyperlipidemia in animal models. Bitter gourd supplements in food result in lowering weight gain and visceral fat mass. This might be due to increase in the level of oxidation of fatty acid and ultimately reduction in weight and peritoneal fat deposition [15]. Most of these studies have been conducted with fruit pulps only. Very little information is available to compare the different parts and formulations of the plant in parallel experiments.

The present study was planned with the objectives to determine hypoglycemic and hypolipidemic effect of bitter gourd on normal, hyperglycemic and hyperlipidemic rats and to identify the part of the plant where the hypoglycemic and hypolipidemic principle is concentrated. Moreover, assessment of different formulations was also undertaken to find the suitable dose under these conditions.

\section{Methods}

\section{Procurement of raw material}

Fruits of bitter gourd were procured from Vegetable Research Section, Ayub Agriculture Research Institute,
Faisalabad. These fruits were washed thoroughly under running tap water to remove adhered dirt, dust and other foreign debris.

\section{Biological assay}

To evaluate the hypoglycemic and hypolipidemic properties of skin, flesh and whole fruit powder of bitter gourd, an efficacy trial was planned. For the purpose, male Sprague Dawley rats were procured from the national institute of health, Islamabad. Initially, the rats were acclimatized by feeding basal diet for 1 week period. The environmental conditions were controlled throughout the trial like temperature $\left(23 \pm 2{ }^{\circ} \mathrm{C}\right)$ and relative humidity $(55 \pm 5 \%)$ along with $12 \mathrm{~h}$ light-dark period. At the initiation of study, some rats were dissected to establish the baseline trend. During efficacy trial, three types of studies were conducted independently by involving normal, hyperglycemic and hyperlipidemic. In Study I, rats were fed on normal diet whereas in study II and study III, high sucrose and high fat diets were administrated, respectively. In the animal modeling, seven groups of rats were formed in three different studies assigning 10 rats in each group. During the entire trial, bitter gourd formulations based feed was given to the respective groups.

\section{Feed plans for experimental rats}

For control group, experimental diet was prepared by using corn oil (10\%), corn starch (66\%), protein (10\%), cellulose $(10 \%)$, mineral (3\%) and vitamin mixture (1\%). In experimental groups, bitter gourd was added in the aforementioned diet (Table 1).

\section{Feed and water intake}

The gross feed intake of each group was calculated every day, excluding the spilled diet throughout the study period. The net water intake was also recorded on daily basis by measuring the difference in graduated bottles.

\section{Body weight gain}

The gain in body weight for each group of rats was monitored on weekly basis to estimate any suppressing effect of bitter gourd formulations.

Table 1 Diet plan used in the studies

\begin{tabular}{llllllllllllllllllllllll}
\hline & \multicolumn{1}{c}{ Study I (Normal diet) } & \multicolumn{1}{c}{ Study II (High sucrose diet) } & \multicolumn{1}{c}{ Study III (High cholesterol diet) } \\
\hline Groups & 1 & 2 & 3 & 4 & 5 & 6 & 7 & 1 & 2 & 3 & 4 & 5 & 6 & 7 & 1 & 2 & 3 & 4 & 5 & 6 & 7 \\
Diet & $\mathrm{D}_{0}$ & $\mathrm{D}_{1}$ & $\mathrm{D}_{2}$ & $\mathrm{D}_{3}$ & $\mathrm{D}_{4}$ & $\mathrm{D}_{5}$ & $\mathrm{D}_{6}$ & $\mathrm{D}_{0}$ & $\mathrm{D}_{1}$ & $\mathrm{D}_{2}$ & $\mathrm{D}_{3}$ & $\mathrm{D}_{4}$ & $\mathrm{D}_{5}$ & $\mathrm{D}_{6}$ & $\mathrm{D}_{0}$ & $\mathrm{D}_{1}$ & $\mathrm{D}_{2}$ & $\mathrm{D}_{3}$ & $\mathrm{D}_{4}$ & $\mathrm{D}_{5}$ & $\mathrm{D}_{6}$ \\
\hline
\end{tabular}

$\mathrm{D}_{0}$ : Control

$\mathrm{D}_{1}$ : Diet containing bitter gourd skin powder $150 \mathrm{mg} / \mathrm{kg}$ of body weight

$\mathrm{D}_{2}$ : Diet containing bitter gourd skin powder $300 \mathrm{mg} / \mathrm{kg}$ of body weight

$D_{3}$ : Diet containing bitter gourd flesh powder $150 \mathrm{mg} / \mathrm{kg}$ of body weight

$\mathrm{D}_{4}$ : Diet containing bitter gourd flesh powder $300 \mathrm{mg} / \mathrm{kg}$ of body weight

$D_{5}$ : Diet containing bitter gourd whole fruit powder $150 \mathrm{mg} / \mathrm{kg}$ of body weight

$D_{6}$ : Diet containing bitter gourd whole fruit powder $300 \mathrm{mg} / \mathrm{kg}$ of body weight 


\section{Hypoglycemic perspectives}

In each group, at respective intervals (4th and 8th week) glucose concentration was estimated by GOD-PAP method as described by Katz et al. [16], whereas, insulin level was estimated by following the instructions of Ahn et al. [17].

\section{Serum lipid profile}

Serum cholesterol level was determined using CHODPAP method [18], low density lipoproteins (LDL) by following the procedure of according to the guidelines of Kim et al. [18], high density lipoprotein (HDL) by HDL Cholesterol Precipitant method [19] and triglycerides level by liquid triglycerides (GPO-PAP) method as described by Kim et al. [18].

\section{Liver functioning tests}

For liver soundness, alanine transferase (ALT), aspartate transferase (AST) and alkaline phosphatase (ALP) were estimated [20]. The ALT and AST levels were measured by dinitrophenylhydrazene (DNPH) through Sigma Kits 58-50 and 59-50, respectively whereas; Alkaline Phosphatase-DGKC was used for ALP assessment.

\section{Kidney functioning tests}

The serum samples were analyzed for urea by GLDHmethod, whilst creatinine by Jaffe procedure via commercial kits to evaluate the kidney functioning [21, 22].

\section{Weight of body organ}

After the trial period, the mice were dissected and body organs like heart, lungs, kidney, liver pancreas and spleen were collected and weighed.

\section{Statistical analysis}

The generated data was being applied by completely randomized design (CRD) and further subjected to statistical analysis using Statistical Package (Microsoft Excel
2010 and Statistix 8.1). Analysis of variance technique (ANOVA) was used to determine the level of significance [23].

\section{Results}

\section{Feed and water intake}

Neither feeding with different parts of bitter gourd fruit nor the variations in concentration of bitter gourd in diet influenced food intake during the experimental period. However, this trait affected significantly with time intervals (weeks) in all studies (Fig. 1). The nonsubstantial effect of addition of bitter gourd in diet on feed intake is in harmony with the findings of Klomann et al. [24]. The different parts and variation in amount of bitter gourd in diet imparted significant effect on water intake in all the studies. The maximum water intake was observed in control group than other groups fed with diet containing bitter gourd (Fig. 2). Shetty et al. [25] reported that water intake increase in diabetic group but the supplementation of bitter gourd in diet significantly decreases the consumption of water. The excessive water intake is a characteristic sign of diabetes. Parmar et al. [26] found that there was an increase in intake of water in diabetic rats as compared to rats of control groups.

\section{Body weight}

Body weight affected substantially with diets containing different parts and concentrations with the passage of time (Fig. 3). It was noted that weight is reduced slightly by giving bitter gourd in rats fed with normal diet while in sucrose and cholesterol fed rats, weight is increased considerably in experimental groups in comparison to their respective control groups. Shetty et al. [25] also found a marginal increase in body weight of diabetic rats fed with diet containing bitter gourd. Similar findings by Hossain et al. [27] also strengthen the current results

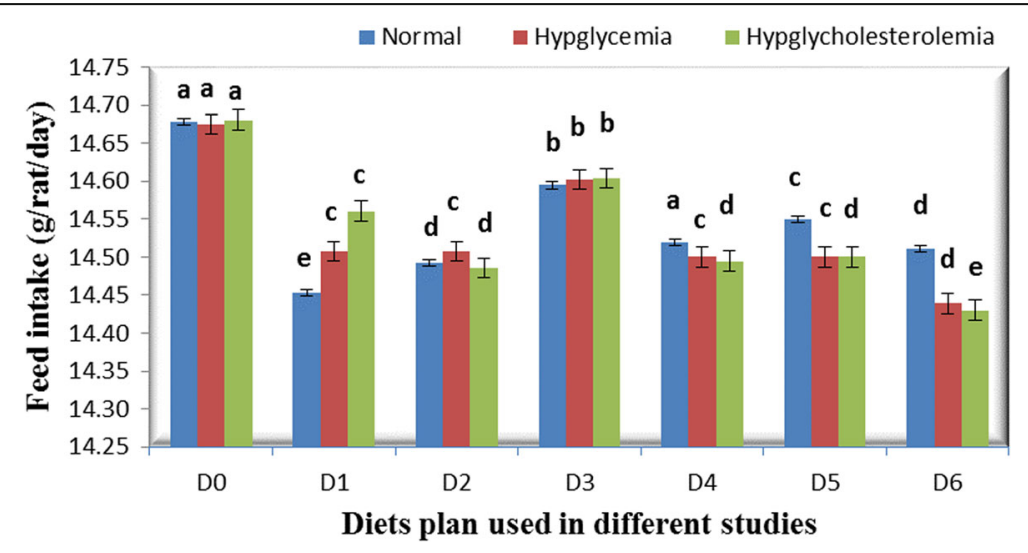

Fig. 1 Feed intake ( $g /$ rat/day) in different studies with different diets 


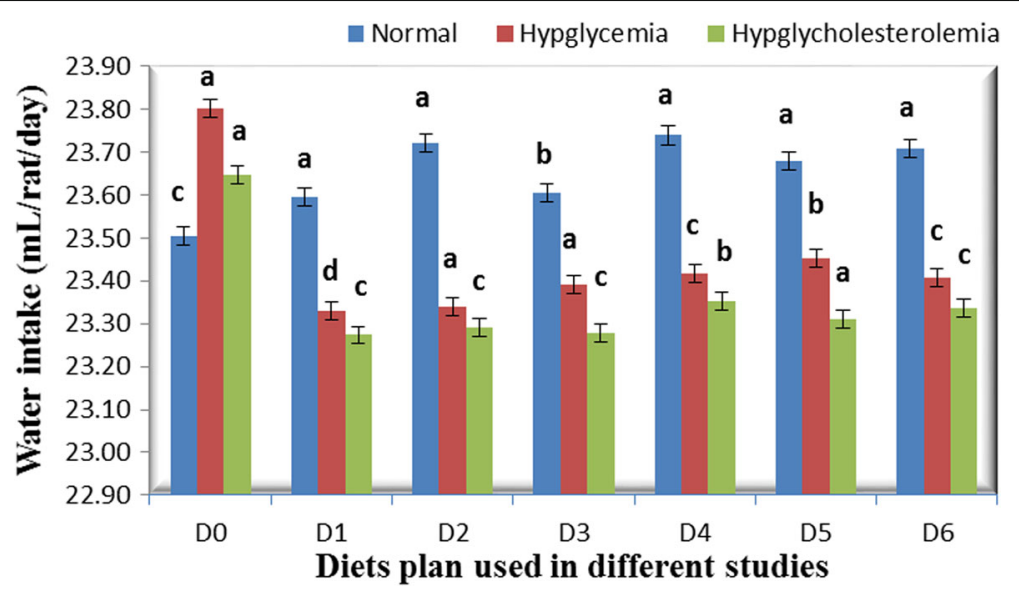

Fig. 2 Water intake $(\mathrm{mL} / \mathrm{rat} /$ day) in different studies with different diets

that body weight of diabetic groups treated with bitter gourd was higher than the untreated diabetic group.

\section{Effect on studied blood parameters}

The results of various blood parameters depicted encouraging effect of utilization of bitter gourd in study I, study II and study III (Table 2, 3 and 4).

\section{Glucose and insulin}

The study intervals led to an enhancement in the glucose level of control groups. However, bitter gourd enriched diets substantially suppressed this trait with passage of time and the lowest glucose concentration was observed in groups of rats fed with $300 \mathrm{mg} / \mathrm{kg}$ body weight of whole fruit of bitter gourd in all the studies (Table 2, 3 and 4). Means concerning insulin were $9.03 \pm 0.31, \quad 9.10 \pm 0.36, \quad 9.33 \pm 0.32, \quad 9.07 \pm 0.35$, $9.37 \pm 0.15,9.13 \pm 0.25$ and $9.87 \pm 0.76 \mu \mathrm{IU} / \mathrm{mL}$ in study I, $12.23 \pm 0.74,14.77 \pm 0.81,14.93 \pm 0.75,14.80 \pm 0.79$, $15.13 \pm 0.49,15.10 \pm 0.30$ and $15.33 \pm 0.25 \mu \mathrm{IU} / \mathrm{mL}$ in study II, $11.37 \pm 0.96,12.00 \pm 0.62,12.93 \pm 0.38,12.17 \pm$ $0.32,12.97 \pm 0.67,12.57 \pm 0.47$ and $13.10 \pm 0.20 \mu \mathrm{IU} / \mathrm{mL}$ in study III for $\mathrm{D}_{0}, \mathrm{D}_{1}, \mathrm{D}_{2}, \mathrm{D}_{3}, \mathrm{D}_{4}, \mathrm{D}_{5}$ and $\mathrm{D}_{6}$ respectively which clearly indicated that increase in amount of bitter gourd in diet has resulted in production of more insulin.

\section{Cholesterol}

Means concerning cholesterol revealed that the highest cholesterol $(85.83 \pm 0.35 \mathrm{mg} / \mathrm{dL})$ was in $D_{0}$ that reduced to $77.13 \pm 1.19\left(\mathrm{D}_{1}\right), 75.90 \pm 2.56 \mathrm{mg} / \mathrm{dL}\left(\mathrm{D}_{5}\right)$, $75.17 \pm 2.22 \mathrm{mg} / \mathrm{dL} \quad\left(\mathrm{D}_{3}\right), \quad 74.67 \pm 1.58 \mathrm{mg} / \mathrm{dL} \quad\left(\mathrm{D}_{6}\right)$, $74.60 \pm 0.98 \mathrm{mg} / \mathrm{dL}\left(\mathrm{D}_{2}\right), 74.00 \pm 0.95 \mathrm{mg} / \mathrm{dL}\left(\mathrm{D}_{4}\right)$ in study I. The study interval of $0,28,56$ day explicated an obvious decrease in cholesterol level from commencement till termination of this study in groups fed with diet containing bitter gourd powder. The cholesterol in diabetic control group $\mathrm{D}_{0}$ (Study II) was $129.07 \pm 1.25 \mathrm{mg} / \mathrm{dL}$ that substantially reduced to $103.07 \pm 1.83,100.80 \pm 1.30,99.50 \pm 1.13,97.97 \pm 1.77$,

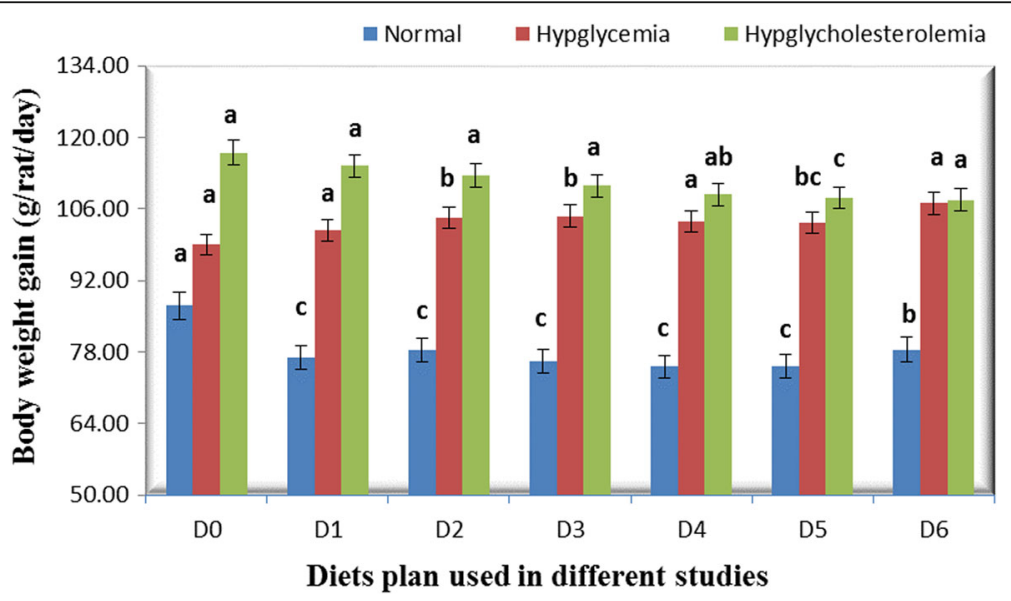

Fig. 3 Body weight gain ( $\mathrm{g} / \mathrm{rat} /$ day) in different studies with different diets 


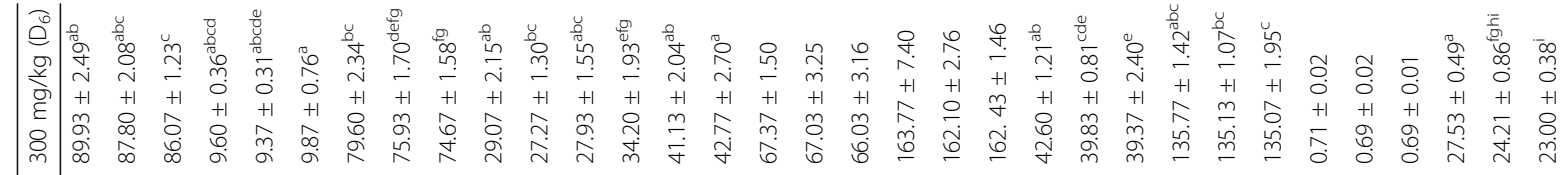

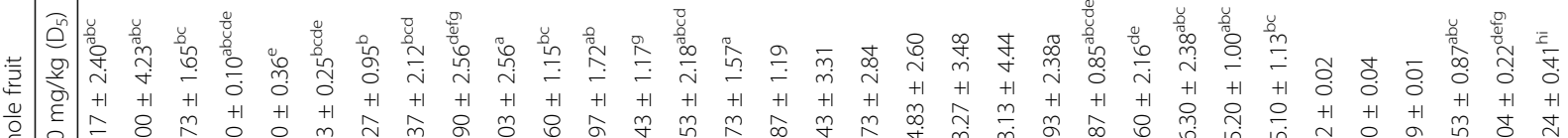

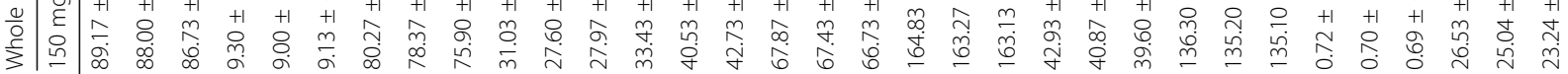

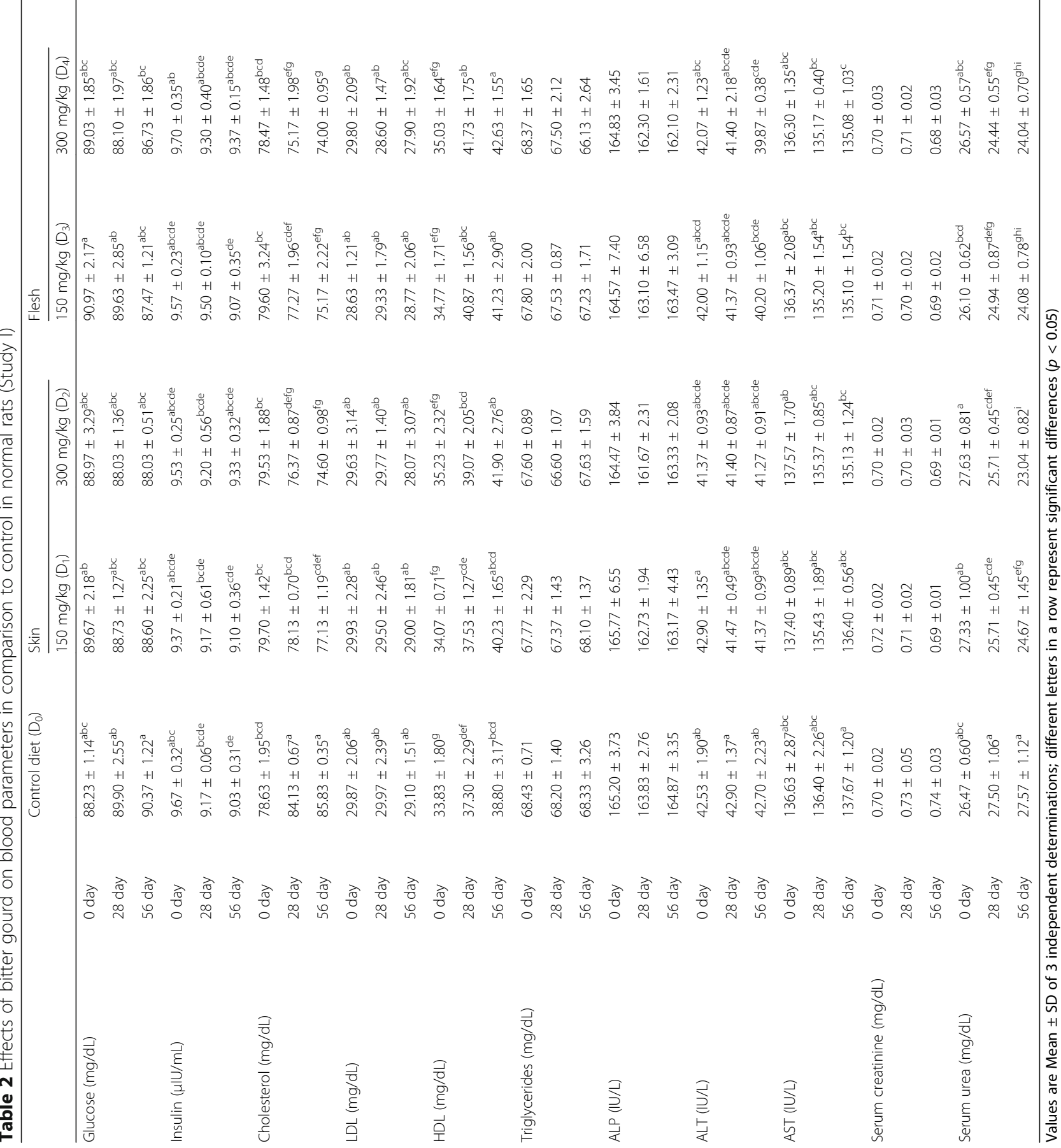


Table 3 Effects of bitter gourd on blood parameters in comparison to control in hyperglycemic rats (Study II)

\begin{tabular}{|c|c|c|c|c|c|c|c|c|}
\hline & & \multirow[t]{2}{*}{ Control diet $\left(D_{0}\right)$} & \multicolumn{2}{|l|}{ Skin } & \multicolumn{2}{|l|}{ Flesh } & \multicolumn{2}{|l|}{ Whole fruit } \\
\hline & & & 150 mg/kg $\left(D_{1}\right)$ & $300 \mathrm{mg} / \mathrm{kg}\left(\mathrm{D}_{2}\right)$ & $150 \mathrm{mg} / \mathrm{kg}\left(\mathrm{D}_{3}\right)$ & 300 mg/kg $\left(D_{4}\right)$ & $150 \mathrm{mg} / \mathrm{kg}\left(\mathrm{D}_{5}\right)$ & 300 mg/kg $\left(D_{6}\right)$ \\
\hline \multirow{3}{*}{$\begin{array}{l}\text { Glucose } \\
\text { (mg/dL) }\end{array}$} & 0 day & $88.17 \pm 0.99^{i}$ & $88.80 \pm 1.61^{i}$ & $89.00 \pm 3.00^{i}$ & $89.10 \pm 1.41^{i}$ & $88.03 \pm 0.91^{i}$ & $89.83 \pm 2.27^{i}$ & $90.40 \pm 1.93^{i}$ \\
\hline & 28 day & $113.80 \pm 2.03^{c}$ & $102.00 \pm 2.26^{\text {def }}$ & $100.33 \pm 1.93^{\mathrm{efg}}$ & $98.13 \pm 1.91^{f g h}$ & $97.00 \pm 1.35^{g h}$ & $97.50 \pm 1.57^{g h}$ & $94.47 \pm 3.70^{h}$ \\
\hline & 56 day & $142.93 \pm 2.70^{\mathrm{a}}$ & $117.83 \pm 3.07^{b}$ & $112.23 \pm 2.46^{c}$ & $110.80 \pm 3.36^{c}$ & $104.53 \pm 4.23^{d}$ & $103.57 \pm 3.00^{\mathrm{de}}$ & $97.70 \pm 2.17^{g h}$ \\
\hline \multirow{3}{*}{$\begin{array}{l}\text { Insulin } \\
(\mu \mathrm{IU} / \mathrm{mL})\end{array}$} & 0 day & $9.40 \pm 0.26^{9}$ & $9.47 \pm 0.23^{9}$ & $9.60 \pm 0.36^{9}$ & $9.63 \pm 0.25^{9}$ & $9.83 \pm 0.51^{9}$ & $9.23 \pm 0.12^{9}$ & $9.50 \pm 0.10^{9}$ \\
\hline & 28 day & $10.80 \pm 0.46^{f}$ & $13.83 \pm 0.76^{d}$ & $14.00 \pm 0.44^{\mathrm{cd}}$ & $13.90 \pm 0.72^{d}$ & $14.50 \pm 0.10^{b c d}$ & $14.40 \pm 0.17^{b c d}$ & $14.97 \pm 0.35^{\mathrm{ab}}$ \\
\hline & 56 day & $12.23 \pm 0.74^{e}$ & $14.77 \pm 0.81^{\mathrm{abc}}$ & $14.93 \pm 0.75^{\mathrm{ab}}$ & $14.80 \pm 0.79^{a b c}$ & $15.13 \pm 0.49^{\mathrm{ab}}$ & $15.10 \pm 0.30^{\mathrm{ab}}$ & $15.33 \pm 0.25^{a}$ \\
\hline \multirow{3}{*}{$\begin{array}{l}\text { Cholesterol } \\
(\mathrm{mg} / \mathrm{dL})\end{array}$} & 0 day & $79.50 \pm 1.13^{e}$ & $79.55 \pm 0.92^{\mathrm{e}}$ & $80.45 \pm 1.77^{e}$ & $79.75 \pm 0.64^{e}$ & $79.65 \pm 0.78^{e}$ & $78.00 \pm 1.84^{\mathrm{e}}$ & $79.80 \pm 2.12^{\mathrm{e}}$ \\
\hline & 28 day & $98.27 \pm 1.12^{c}$ & $91.87 \pm 1.34^{d}$ & $90.50 \pm 1.44^{d}$ & $90.40 \pm 2.98^{d}$ & $89.87 \pm 1.00^{d}$ & $90.63 \pm 2.45^{d}$ & $90.20 \pm 3.38^{d}$ \\
\hline & 56 day & $129.07 \pm 1.25^{\mathrm{a}}$ & $103.07 \pm 1.83^{b}$ & $100.80 \pm 1.30^{b c}$ & $99.50 \pm 1.13^{b c}$ & $97.97 \pm 1.77^{c}$ & $98.37 \pm 1.52^{c}$ & $98.00 \pm 3.22^{c}$ \\
\hline \multirow{3}{*}{$\begin{array}{l}\mathrm{LDL} \\
\text { (mg/dL) }\end{array}$} & 0 day & $29.53 \pm 3.23^{\mathrm{hi}}$ & $28.87 \pm 1.37^{h i}$ & $29.30 \pm 2.57^{h i}$ & $28.17 \pm 1.45^{i}$ & $28.93 \pm 2.66^{\mathrm{hi}}$ & $28.70 \pm 1.55^{\mathrm{hi}}$ & $28.07 \pm 1.46^{i}$ \\
\hline & 28 day & $38.93 \pm 1.55^{f}$ & $33.63 \pm 1.45^{9}$ & $32.10 \pm 2.11^{g h}$ & $31.80 \pm 1.95^{\mathrm{gh}}$ & $29.77 \pm 2.49^{h i}$ & $31.40 \pm 3.02^{g h i}$ & $29.17 \pm 1.85^{h i}$ \\
\hline & 56 day & $63.85 \pm 2.47^{a}$ & $55.80 \pm 1.87^{b}$ & $51.07 \pm 1.77^{c}$ & $49.67 \pm 2.40^{c d}$ & $46.33 \pm 2.80^{\mathrm{de}}$ & $49.57 \pm 1.55^{\mathrm{cd}}$ & $45.63 \pm 2.51^{\mathrm{e}}$ \\
\hline \multirow{3}{*}{$\begin{array}{l}\mathrm{HDL} \\
(\mathrm{mg} / \mathrm{dL})\end{array}$} & 0 day & $34.93 \pm 2.37^{\mathrm{de}}$ & $35.20 \pm 1.55^{\mathrm{de}}$ & $34.90 \pm 2.23^{\mathrm{de}}$ & $35.10 \pm 2.66^{\mathrm{de}}$ & $34.50 \pm 1.57^{\mathrm{de}}$ & $34.77 \pm 0.99^{\text {de }}$ & $33.53 \pm 0.93^{e}$ \\
\hline & 28 day & $35.93 \pm 2.27^{\text {de }}$ & $37.23 \pm 0.95^{d}$ & $41.73 \pm 2.24^{c}$ & $41.60 \pm 1.51^{c}$ & $41.73 \pm 1.75^{c}$ & $40.87 \pm 1.99^{c}$ & $42.00 \pm 1.90^{c}$ \\
\hline & 56 day & $35.97 \pm 2.25^{\mathrm{de}}$ & $42.23 \pm 1.19^{c}$ & $43.23 \pm 1.17^{b c}$ & $42.90 \pm 1.61^{b c}$ & $43.30 \pm 0.98^{\mathrm{ab}}$ & $45.63 \pm 2.80^{\mathrm{ab}}$ & $47.43 \pm 1.12^{\mathrm{a}}$ \\
\hline \multirow{3}{*}{$\begin{array}{l}\text { Triglycerides } \\
\text { (mg/dL) }\end{array}$} & 0 day & $67.43 \pm 0.76^{9}$ & $68.30 \pm 1.21^{9}$ & $68.40 \pm 2.11^{9}$ & $68.03 \pm 2.31^{9}$ & $68.13 \pm 1.98^{9}$ & $68.93 \pm 1.32^{9}$ & $67.53 \pm 0.78^{9}$ \\
\hline & 28 day & $81.43 \pm 2.70^{\text {de }}$ & $78.37 \pm 1.56^{\mathrm{ef}}$ & $77.37 \pm 2.43^{f}$ & $77.33 \pm 1.53^{f}$ & $76.53 \pm 2.15^{f}$ & $77.30 \pm 1.70^{f}$ & $76.30 \pm 2.80^{f}$ \\
\hline & 56 day & $92.87 \pm 3.80^{\mathrm{a}}$ & $87.00 \pm 2.66^{b}$ & $85.43 \pm 1.01^{b c}$ & $85.53 \pm 1.60^{b c}$ & $85.10 \pm 1.64^{b c}$ & $84.90 \pm 2.76^{\mathrm{bc}}$ & $82.37 \pm 2.44^{c d}$ \\
\hline \multirow{3}{*}{$\begin{array}{l}\text { ALP } \\
(I U / L)\end{array}$} & 0 day & $165.33 \pm 4.52^{\mathrm{e}}$ & $164.10 \pm 5.85^{\mathrm{e}}$ & $164.90 \pm 1.51^{\mathrm{e}}$ & $164.53 \pm 2.01^{\mathrm{e}}$ & $165.63 \pm 4.87^{\mathrm{e}}$ & $164.20 \pm 3.28^{\mathrm{e}}$ & $164.73 \pm 3.54^{\mathrm{e}}$ \\
\hline & 28 day & $193.43 \pm 2.54^{b}$ & $189.80 \pm 6.12^{\mathrm{bcd}}$ & $187.47 \pm 4.66^{\mathrm{bcd}}$ & $185.63 \pm 4.57^{\mathrm{cd}}$ & $184.33 \pm 2.06^{d}$ & $184.50 \pm 3.68^{d}$ & $184.33 \pm 5.66^{d}$ \\
\hline & 56 day & $203.40 \pm 2.46^{a}$ & $193.67 \pm 3.91^{b}$ & $193.60 \pm 3.05^{b}$ & $191.53 \pm 3.51^{b c}$ & $191.20 \pm 2.65^{b c}$ & $191.47 \pm 4.28^{b c}$ & $187.83 \pm 1.89^{\mathrm{bcd}}$ \\
\hline \multirow{3}{*}{$\begin{array}{l}\mathrm{ALT} \\
(\mathrm{IU} / \mathrm{L})\end{array}$} & 0 day & $42.63 \pm 0.90^{b c d}$ & $42.20 \pm 1.31^{\mathrm{bcd}}$ & $42.83 \pm 1.75^{\mathrm{bcd}}$ & $41.17 \pm 1.08^{\mathrm{d}}$ & $42.17 \pm 0.90^{\mathrm{bcd}}$ & $42.00 \pm 2.39^{c d}$ & $41.03 \pm 2.18^{d}$ \\
\hline & 28 day & $44.23 \pm 1.88^{b c}$ & $42.47 \pm 0.93^{\mathrm{bcd}}$ & $42.23 \pm 1.70^{\mathrm{bcd}}$ & $42.13 \pm 1.10^{\mathrm{bcd}}$ & $41.30 \pm 0.87^{d}$ & $41.93 \pm 0.47^{c d}$ & $41.83 \pm 2.76^{\mathrm{cd}}$ \\
\hline & 56 day & $49.37 \pm 0.70^{a}$ & $44.57 \pm 0.83^{b}$ & $43.93 \pm 1.56^{\mathrm{bc}}$ & $43.87 \pm 1.63^{\mathrm{bc}}$ & $43.30 \pm 1.11^{\mathrm{bcd}}$ & $43.37 \pm 1.16^{\mathrm{bcd}}$ & $43.20 \pm 1.42^{\mathrm{bcd}}$ \\
\hline \multirow{3}{*}{$\begin{array}{l}\text { AST } \\
(I U / L)\end{array}$} & 0 day & $135.27 \pm 2.55^{9}$ & $136.90 \pm 0.44^{9}$ & $136.97 \pm 1.67^{9}$ & $136.70 \pm 1.00^{9}$ & $137.10 \pm 0.62^{9}$ & $136.13 \pm 0.67^{9}$ & $136.43 \pm 0.93^{9}$ \\
\hline & 28 day & $146.67 \pm 2.29^{b}$ & $142.57 \pm 1.96^{\text {cdef }}$ & $142.37 \pm 2.06^{e f}$ & $142.50 \pm 1.64^{\text {def }}$ & $142.27 \pm 0.90^{\mathrm{ef}}$ & $142.07 \pm 1.12^{f}$ & $141.90 \pm 0.85^{f}$ \\
\hline & 56 day & $151.93 \pm 2.10^{a}$ & $145.40 \pm 1.35^{b}$ & $145.13 \pm 1.24^{b}$ & $145.20 \pm 1.54^{b}$ & $144.83 \pm 1.42^{\mathrm{bcd}}$ & $145.00 \pm 1.41^{b c}$ & $144.60 \pm 1.31^{\text {bcde }}$ \\
\hline \multirow{3}{*}{$\begin{array}{l}\text { Serum } \\
\text { creatinine } \\
\text { (mg/dL) }\end{array}$} & 0 day & $0.74 \pm 0.04^{\mathrm{de}}$ & $0.74 \pm 0.05^{\mathrm{de}}$ & $0.73 \pm 0.01^{e}$ & $0.72 \pm 0.02^{e}$ & $0.74 \pm 0.01^{\mathrm{de}}$ & $0.73 \pm 0.03^{e}$ & $0.73 \pm 0.02^{e}$ \\
\hline & 28 day & $0.91 \pm 0.03^{a}$ & $0.87 \pm 0.02^{b}$ & $0.86 \pm 0.02^{b}$ & $0.86 \pm 0.02^{b}$ & $0.85 \pm 0.01^{b}$ & $0.85 \pm 0.01^{b}$ & $0.84 \pm 0.01^{b}$ \\
\hline & 56 day & $0.91 \pm 0.03^{\mathrm{a}}$ & $0.80 \pm 0.02^{c}$ & $0.79 \pm 0.03^{c}$ & $0.79 \pm 0.03^{c}$ & $0.78 \pm 0.02^{c}$ & $0.78 \pm 0.02^{c}$ & $0.77 \pm 0.01^{c d}$ \\
\hline \multirow{3}{*}{$\begin{array}{l}\text { Serum urea } \\
(\mathrm{mg} / \mathrm{dL})\end{array}$} & 0 day & $27.21 \pm 1.03^{\mathrm{bcd}}$ & $27.31 \pm 0.75^{\mathrm{bcd}}$ & $27.90 \pm 2.11^{\mathrm{bcd}}$ & $27.20 \pm 0.40^{\mathrm{bcd}}$ & $27.80 \pm 1.49^{\mathrm{bcd}}$ & $25.90 \pm 1.44^{d}$ & $27.57 \pm 1.01^{\mathrm{bcd}}$ \\
\hline & 28 day & $30.90 \pm 1.56^{\mathrm{a}}$ & $28.67 \pm 0.87^{b}$ & $28.30 \pm 1.40^{\mathrm{bc}}$ & $27.60 \pm 1.93^{\mathrm{bcd}}$ & $27.43 \pm 1.10^{\mathrm{bcd}}$ & $26.93 \pm 0.81^{\mathrm{bcd}}$ & $26.67 \pm 1.03^{\mathrm{bcd}}$ \\
\hline & 56 day & $32.48 \pm 1.13^{\mathrm{a}}$ & $27.75 \pm 0.90^{\mathrm{bcd}}$ & $27.47 \pm 1.14^{\mathrm{bcd}}$ & $27.17 \pm 2.05^{\mathrm{bcd}}$ & $27.10 \pm 1.51^{\mathrm{bcd}}$ & $26.73 \pm 1.15^{\mathrm{bcd}}$ & $26.21 \pm 1.58^{\mathrm{cd}}$ \\
\hline
\end{tabular}

Values are Mean \pm SD of 3 independent determinations; different letters in a row represent significant differences $(p<0.05)$

$98.37 \pm 1.52$ and $98.00 \pm 3.22 \mathrm{mg} / \mathrm{dL}$ in $\mathrm{D}_{1}, \mathrm{D}_{2}, \mathrm{D}_{3}, \mathrm{D}_{4}$, $\mathrm{D}_{5}$ and $\mathrm{D}_{6}$ respectively. In Hypercholesterolemic rats (Study III), enormous increase in cholesterol was observed in control group $\mathrm{D}_{0}(160.67 \pm 4.16 \mathrm{mg} / \mathrm{dL})$ while experimental groups fed with bitter gourd showed reduction in the level of cholesterol as $129.33 \pm 2.52, \quad 125.30 \pm 3.08, \quad 123.37 \pm 3.28, \quad 116.70 \pm$ $2.54,124.70 \pm 2.86$ and $118.83 \pm 1.91 \mathrm{mg} / \mathrm{dL}$ in $\mathrm{D}_{1}, \mathrm{D}_{2}$, $\mathrm{D}_{3}, \mathrm{D}_{4}, \mathrm{D}_{5}$ and $\mathrm{D}_{6}$, respectively. The study interval of $0,28,56$ day explicated an obvious decrease in cholesterol level from commencement till termination of the study in groups fed with diet containing bitter gourd powder.

\section{LDL}

LDL level was varied insignificantly from initiation to termination of trial $(0,28$ th \& 56th day) in study I. In this study, maximum LDL level was observed in $\mathrm{D}_{0}$ as $29.10 \pm 1.51 \mathrm{mg} / \mathrm{dL}$ that substantially reduced in $\mathrm{D}_{1}(29.00 \pm 1.81 \mathrm{mg} / \mathrm{dL})$ trailed by $\mathrm{D}_{3}$ 
Table 4 Effects of bitter gourd on blood parameters in comparison to control in hyperlipidemic rats (Study III)

\begin{tabular}{|c|c|c|c|c|c|c|c|c|}
\hline & & \multirow[t]{2}{*}{ Control diet $\left(D_{0}\right)$} & \multicolumn{2}{|l|}{ Skin } & \multicolumn{2}{|l|}{ Flesh } & \multicolumn{2}{|l|}{ Whole fruit } \\
\hline & & & $150 \mathrm{mg} / \mathrm{kg}\left(\mathrm{D}_{1}\right)$ & $300 \mathrm{mg} / \mathrm{kg}\left(\mathrm{D}_{2}\right)$ & $150 \mathrm{mg} / \mathrm{kg}\left(\mathrm{D}_{3}\right)$ & $300 \mathrm{mg} / \mathrm{kg}\left(\mathrm{D}_{4}\right)$ & $150 \mathrm{mg} / \mathrm{kg}\left(\mathrm{D}_{5}\right)$ & $300 \mathrm{mg} / \mathrm{kg}\left(\mathrm{D}_{6}\right)$ \\
\hline \multirow{3}{*}{$\begin{array}{l}\text { Glucose } \\
\text { (mg/dL) }\end{array}$} & 0 day & $87.50 \pm 0.80^{h}$ & $87.97 \pm 0.67^{h}$ & $88.63 \pm 1.38^{h}$ & $89.50 \pm 1.57^{h}$ & $88.80 \pm 1.31^{h}$ & $88.50 \pm 2.08^{h}$ & $87.83 \pm 2.00^{h}$ \\
\hline & 28 day & $98.43 \pm 1.21^{\text {bcde }}$ & $96.77 \pm 1.25^{\text {def }}$ & $96.40 \pm 1.23^{\mathrm{def}}$ & $96.10 \pm 2.13^{\text {defg }}$ & $95.40 \pm 2.39^{\mathrm{fg}}$ & $95.70 \pm 1.84^{\mathrm{efg}}$ & $94.63 \pm 1.72^{\mathrm{fg}}$ \\
\hline & 56 day & $106.33 \pm 2.52^{\mathrm{a}}$ & $100.33 \pm 1.53^{b}$ & $99.87 \pm 1.86^{\mathrm{bc}}$ & $98.57 \pm 1.03^{\mathrm{bcd}}$ & $97.30 \pm 2.56^{\text {cdef }}$ & $95.27 \pm 1.99^{f g}$ & $93.50 \pm 0.60^{9}$ \\
\hline \multirow{3}{*}{$\begin{array}{l}\text { Insulin } \\
(\mu \mid \mathrm{U} / \mathrm{mL})\end{array}$} & 0 day & $9.53 \pm 0.15^{h}$ & $9.57 \pm 0.12^{h}$ & $9.66 \pm 0.23^{h}$ & $9.36 \pm 0.27^{h}$ & $9.68 \pm 0.91^{h}$ & $9.86 \pm 0.19^{h}$ & $9.57 \pm 0.74^{h}$ \\
\hline & 28 day & $10.67 \pm 0.75^{9}$ & $10.87 \pm 0.74^{9}$ & $11.07 \pm 0.67^{f g}$ & $10.77 \pm 0.46^{9}$ & $11.27 \pm 0.32^{\mathrm{efg}}$ & $11.20 \pm 0.46^{\mathrm{efg}}$ & $11.83 \pm 0.64^{\text {cdef }}$ \\
\hline & 56 day & $11.37 \pm 0.96^{\text {defg }}$ & $12.00 \pm 0.62^{\mathrm{cde}}$ & $12.93 \pm 0.38^{\mathrm{ab}}$ & $12.17 \pm 0.32^{\mathrm{bcd}}$ & $12.97 \pm 0.67^{\mathrm{ab}}$ & $12.57 \pm 0.47^{\mathrm{abc}}$ & $13.10 \pm 0.20^{\mathrm{a}}$ \\
\hline \multirow{3}{*}{$\begin{array}{l}\text { Cholesterol } \\
(\mathrm{mg} / \mathrm{dL})\end{array}$} & 0 day & $80.77 \pm 3.15^{\mathrm{h}}$ & $80.47 \pm 3.72^{h}$ & $79.90 \pm 2.01^{\mathrm{h}}$ & $79.47 \pm 3.07^{\mathrm{h}}$ & $80.47 \pm 2.34^{h}$ & $79.53 \pm 3.43^{h}$ & $78.67 \pm 3.06^{h}$ \\
\hline & 28 day & $128.00 \pm 4.36^{b c}$ & $114.87 \pm 3.82^{\mathrm{ef}}$ & $109.33 \pm 2.42^{\mathrm{g}}$ & $110.67 \pm 1.31^{\mathrm{fg}}$ & $107.40 \pm 2.26^{9}$ & $107.33 \pm 1.53^{9}$ & $109.33 \pm 4.86^{9}$ \\
\hline & 56 day & $160.67 \pm 4.16^{\mathrm{a}}$ & $129.33 \pm 2.52^{b}$ & $125.30 \pm 3.08^{b c}$ & $123.37 \pm 3.28^{\mathrm{cd}}$ & $116.70 \pm 2.54^{\mathrm{e}}$ & $124.70 \pm 2.86^{\mathrm{bc}}$ & $118.83 \pm 1.91^{\mathrm{de}}$ \\
\hline \multirow{3}{*}{$\begin{array}{l}\mathrm{LDL} \\
\text { (mg/dL) }\end{array}$} & 0 day & $29.73 \pm 3.87^{i}$ & $28.63 \pm 1.08^{i}$ & $29.03 \pm 2.75^{i}$ & $28.67 \pm 2.15^{i}$ & $27.90 \pm 0.89^{i}$ & $28.30 \pm 2.10^{\mathrm{i}}$ & $28.73 \pm 1.50^{i}$ \\
\hline & 28 day & $49.40 \pm 1.35^{f}$ & $40.57 \pm 1.63^{9}$ & $40.17 \pm 1.27^{9}$ & $39.57 \pm 1.53 \mathrm{gh}$ & $39.00 \pm 0.26^{g h}$ & $37.37 \pm 2.30^{g h}$ & $36.13 \pm 1.63^{h}$ \\
\hline & 56 day & $74.33 \pm 3.31^{a}$ & $63.20 \pm 3.51^{b}$ & $60.23 \pm 3.40^{b c}$ & $57.00 \pm 1.28^{\mathrm{cd}}$ & $54.67 \pm 2.40^{\text {de }}$ & $54.57 \pm 1.55^{\mathrm{de}}$ & $53.20 \pm 2.54^{\mathrm{e}}$ \\
\hline \multirow{3}{*}{$\begin{array}{l}\mathrm{HDL} \\
(\mathrm{mg} / \mathrm{dL})\end{array}$} & 0 day & $34.57 \pm 2.12^{h}$ & $34.27 \pm 1.06^{h}$ & $34.83 \pm 2.80^{h}$ & $32.23 \pm 1.68^{\mathrm{h}}$ & $34.30 \pm 1.45^{h}$ & $34.83 \pm 1.75^{h}$ & $33.40 \pm 1.35^{h}$ \\
\hline & 28 day & $35.93 \pm 1.46^{g h}$ & $39.13 \pm 1.24^{\mathrm{fg}}$ & $42.40 \pm 3.20^{\mathrm{ef}}$ & $43.07 \pm 3.82^{\text {def }}$ & $43.33 \pm 2.69^{\text {de }}$ & $45.73 \pm 2.74^{\text {bcde }}$ & $47.70 \pm 1.31^{\mathrm{abc}}$ \\
\hline & 56 day & $35.97 \pm 1.72^{g h}$ & $44.90 \pm 2.41^{\mathrm{cde}}$ & $47.03 \pm 2.85^{\mathrm{bcd}}$ & $46.00 \pm 2.69^{b c d e}$ & $49.30 \pm 1.97^{\mathrm{ab}}$ & $49.20 \pm 4.68^{\mathrm{ab}}$ & $51.63 \pm 4.07^{\mathrm{a}}$ \\
\hline \multirow{3}{*}{$\begin{array}{l}\text { Triglycerides } \\
\text { (mg/dL) }\end{array}$} & 0 day & $67.70 \pm 2.12^{\mathrm{e}}$ & $68.27 \pm 1.06^{\mathrm{e}}$ & $67.63 \pm 2.80^{\mathrm{e}}$ & $68.80 \pm 1.68^{\mathrm{e}}$ & $69.17 \pm 1.45^{\mathrm{e}}$ & $68.70 \pm 1.75^{\mathrm{e}}$ & $67.37 \pm 1.35^{\mathrm{e}}$ \\
\hline & 28 day & $96.67 \pm 4.09^{c}$ & $81.67 \pm 2.18^{d}$ & $80.10 \pm 2.46^{d}$ & $81.03 \pm 3.10^{d}$ & $79.43 \pm 1.63^{d}$ & $78.57 \pm 3.19^{d}$ & $77.03 \pm 2.75^{d}$ \\
\hline & 56 day & $124.67 \pm 3.06^{\mathrm{a}}$ & $103.57 \pm 3.37^{b}$ & $99.70 \pm 1.25^{b c}$ & $99.27 \pm 4.34^{b c}$ & $99.23 \pm 5.19^{b c}$ & $98.67 \pm 2.34^{c}$ & $98.23 \pm 4.47^{c}$ \\
\hline \multirow{3}{*}{$\begin{array}{l}\text { ALP } \\
(I U / L)\end{array}$} & 0 day & $163.93 \pm 3.04^{f}$ & $162.27 \pm 4.73^{f}$ & $165.07 \pm 3.21^{f}$ & $164.93 \pm 4.46^{f}$ & $165.37 \pm 3.75^{f}$ & $163.87 \pm 3.21^{f}$ & $164.40 \pm 1.66^{f}$ \\
\hline & 28 day & $196.13 \pm 1.70^{b}$ & $190.37 \pm 5.93^{\text {bcde }}$ & $187.53 \pm 5.15^{\mathrm{de}}$ & $186.43 \pm 3.57^{\mathrm{de}}$ & $187.00 \pm 3.65^{\mathrm{de}}$ & $186.17 \pm 2.27^{\mathrm{de}}$ & $185.00 \pm 3.60^{e}$ \\
\hline & 56 day & $210.43 \pm 4.04^{\mathrm{a}}$ & $194.67 \pm 2.28^{b c}$ & $194.57 \pm 3.44^{b c}$ & $192.03 \pm 4.24^{\mathrm{bcd}}$ & $191.53 \pm 3.21^{\mathrm{bcd}}$ & $191.30 \pm 4.55^{\mathrm{bcd}}$ & $189.03 \pm 3.48^{\text {cde }}$ \\
\hline \multirow{3}{*}{$\begin{array}{l}\mathrm{ALT} \\
(\mathrm{IU} / \mathrm{L})\end{array}$} & 0 day & $42.27 \pm 1.25^{\mathrm{fg}}$ & $42.37 \pm 0.80^{f g}$ & $41.17 \pm 0.40^{9}$ & $42.03 \pm 1.46^{\mathrm{fg}}$ & $41.20 \pm 1.49^{9}$ & $42.00 \pm 1.55^{\mathrm{fg}}$ & $41.43 \pm 1.33^{9}$ \\
\hline & 28 day & $47.80 \pm 1.23^{b c}$ & $43.40 \pm 0.56 e^{f g}$ & $43.30 \pm 1.92^{\mathrm{efg}}$ & $43.40 \pm 0.82^{\mathrm{efg}}$ & $43.03 \pm 1.26^{\mathrm{fg}}$ & $43.27 \pm 1.04^{\mathrm{fg}}$ & $43.07 \pm 1.00^{\mathrm{fg}}$ \\
\hline & 56 day & $53.77 \pm 1.76^{\mathrm{a}}$ & $48.77 \pm 1.50^{b}$ & $47.27 \pm 0.91^{b c}$ & $46.50 \pm 3.18^{\mathrm{bcd}}$ & $45.87 \pm 1.53^{\text {cde }}$ & $44.57 \pm 3.10^{\text {def }}$ & $44.17 \pm 1.70^{\text {def }}$ \\
\hline \multirow{3}{*}{$\begin{array}{l}\text { AST } \\
(I U / L)\end{array}$} & 0 day & $136.03 \pm 1.22^{\mathrm{e}}$ & $137.00 \pm 0.78^{e}$ & $136.63 \pm 0.76^{e}$ & $136.47 \pm 0.93^{e}$ & $136.43 \pm 0.85^{e}$ & $137.23 \pm 0.55^{e}$ & $135.73 \pm 1.11^{\mathrm{e}}$ \\
\hline & 28 day & $156.00 \pm 1.73^{c}$ & $148.07 \pm 0.71^{d}$ & $147.70 \pm 2.02^{d}$ & $148.07 \pm 1.12^{d}$ & $147.27 \pm 1.10^{d}$ & $147.47 \pm 1.52^{d}$ & $147.83 \pm 1.05^{d}$ \\
\hline & 56 day & $172.67 \pm 2.11^{a}$ & $162.07 \pm 1.99^{b}$ & $161.67 \pm 1.46^{b}$ & $161.87 \pm 2.03^{b}$ & $161.50 \pm 1.47^{b}$ & $161.13 \pm 1.79^{b}$ & $161.53 \pm 1.70^{b}$ \\
\hline \multirow{3}{*}{$\begin{array}{l}\text { Serum } \\
\text { creatinine } \\
\text { (mg/dL) }\end{array}$} & 0 day & $0.73 \pm 0.02^{f}$ & $0.75 \pm 0.02^{f}$ & $0.74 \pm 0.01^{f}$ & $0.73 \pm 0.02^{f}$ & $0.75 \pm 0.01^{f}$ & $0.72 \pm 0.02^{f}$ & $0.73 \pm 0.02^{f}$ \\
\hline & 28 day & $0.98 \pm 0.98^{b}$ & $0.91 \pm 0.91^{c}$ & $0.89 \pm 0.89^{c}$ & $0.91 \pm 0.91^{c}$ & $0.89 \pm 0.89^{c}$ & $0.89 \pm 0.89^{c}$ & $0.88 \pm 0.88^{\mathrm{cd}}$ \\
\hline & 56 day & $1.17 \pm 0.05^{\mathrm{a}}$ & $0.84 \pm 0.03^{\mathrm{de}}$ & $0.83 \pm 0.04^{e}$ & $0.84 \pm 0.02^{\mathrm{de}}$ & $0.82 \pm 0.02^{e}$ & $0.82 \pm 0.01^{e}$ & $0.81 \pm 0.01^{e}$ \\
\hline \multirow{3}{*}{$\begin{array}{l}\text { Serum urea } \\
(\mathrm{mg} / \mathrm{dL})\end{array}$} & 0 day & $26.23 \pm 0.29^{f}$ & $26.73 \pm 0.84^{e f}$ & $27.07 \pm 1.25^{\mathrm{ef}}$ & $26.67 \pm 0.68^{e f}$ & $27.16 \pm 1.01^{\mathrm{ef}}$ & $27.25 \pm 0.27^{\mathrm{ef}}$ & $28.05 \pm 0.68^{\mathrm{e}}$ \\
\hline & 28 day & $35.07 \pm 2.65^{b}$ & $32.83 \pm 1.63^{\mathrm{cd}}$ & $32.53 \pm 0.83^{c d}$ & $32.43 \pm 1.20^{c d}$ & $32.29 \pm 0.52^{\mathrm{cd}}$ & $31.57 \pm 0.96^{\mathrm{d}}$ & $31.40 \pm 0.89^{d}$ \\
\hline & 56 day & $37.47 \pm 1.12^{\mathrm{a}}$ & $34.00 \pm 0.75^{b c}$ & $33.13 \pm 0.29^{c d}$ & $33.07 \pm 1.31^{\mathrm{cd}}$ & $32.50 \pm 0.52^{\mathrm{cd}}$ & $33.00 \pm 0.61^{c d}$ & $32.23 \pm 1.15^{d}$ \\
\hline
\end{tabular}

Values are Mean \pm SD of 3 independent determinations; different letters in a row represent significant differences $(p<0.05)$

$(28.77 \pm 2.06 \mathrm{mg} / \mathrm{dL}), \mathrm{D}_{2}(28.07 \pm 3.072 \mathrm{mg} / \mathrm{dL}), \mathrm{D}_{5}$ $(27.97 \pm 1.72 \mathrm{mg} / \mathrm{dL}), \mathrm{D}_{6}(27.93 \pm 1.55 \mathrm{mg} / \mathrm{dL})$ and $\mathrm{D}_{4}(27.90 \pm 1.92 \mathrm{mg} / \mathrm{dL})$. In study $\mathrm{II}$, the recorded values showed a diminishing trend in LDL level with values of $55.80 \pm 1.87, \quad 51.07 \pm 1.77, \quad 49.67 \pm 2.40$, $46.33 \pm 2.80,49.57 \pm 1.55,45.63 \pm 2.51 \mathrm{mg} / \mathrm{dL}$ in $\mathrm{D}_{1}$, $\mathrm{D}_{2}, \mathrm{D}_{3}, \mathrm{D}_{4}, \mathrm{D}_{5}$ and $\mathrm{D}_{6}$, respectively compared to control group $\mathrm{D}_{0}(63.85 \pm 2.47 \mathrm{mg} / \mathrm{dL})$. Similarly, the highest value of LDL was in control group (74.33 \pm $3.31 \mathrm{mg} / \mathrm{dL})$ followed by $\mathrm{D}_{1}(63.20 \pm 3.51 \mathrm{mg} / \mathrm{dL}), \mathrm{D}_{2}$
$(60.23 \pm 3.40 \mathrm{mg} / \mathrm{dL}), \quad \mathrm{D}_{3} \quad(57.00 \pm 1.28 \mathrm{mg} / \mathrm{dL}), \quad \mathrm{D}_{4}$ $(54.67 \pm 2.40 \mathrm{mg} / \mathrm{dL}), \quad D_{5}(54.57 \pm 1.55 \mathrm{mg} / \mathrm{dL})$ and $\mathrm{D}_{6}(53.20 \pm 2.54 \mathrm{mg} / \mathrm{dL})$ indicated that bitter gourd powder in diet is helpful in lowering LDL level. The low density lipoproteins are the major carrier for cholesterol in blood [28]. Bitter gourd has the ability to reduce this 'bad cholesterol' from the blood. Temitope et al. [29] orally administered aqueous extract of bitter gourd at dose of 80, 100, 120, $140 \mathrm{mg} / \mathrm{kg}$ body weight for 14 days. Significant 
decline in LDL in experimental groups were observed compared to rats fed with normal diet.

\section{$\mathrm{HDL}$}

HDL values increased after consumption of bitter gourd in diet. The study interval influenced significantly on the increase in HDL level and the highest increase was observed in $\mathrm{D}_{6}$ in all the studies. The higher amount of HDL in blood is considered valuable because it is found good for health and mostly designated as 'good cholesterol'. The decline in HDL concentration in blood leads to wide ranging cardiovascular complications. Bitter gourd in diet is helpful in increasing the level of HDL in blood. Bano et al. [30] revealed that increased the serum HDL level rise up to $45 \%$ by administering aqueous extract of bitter gourd for 5 weeks. Temitope et al. [29] examined different doses of bitter gourd to analyze HDL level in blood and found diets containing $100 \mathrm{mg} / \mathrm{kg}$ and $140 \mathrm{mg} / \mathrm{kg}$ body weight as suitable dietary approaches and resulted in marked increase in the HDL level than the rest of the treatments.

\section{Triglycerides}

The values for triglycerides rise gradually in control group while reduction was observed by supplementation of bitter gourd in diet. Consistent with current results, Jayasooria et al. [31] determined the effect of bitter gourd on lipid metabolism and found significant reduction of 39.2 and $40.5 \%$ in hepatic triglycerides in cholesterol rich and cholesterol free diets, respectively. The present results also supported by the findings of Bano et al. [30] determined $20 \%$ decline in serum triglyceride level due to dietary intake of bitter gourd in diabetic rats. Hossain et al. [27] observed significant elevation in triglycerides level (47.02\%) in diabetic control rat groups. However, bitter gourd at the rate of $250,500,750 \mathrm{mg}$ reduced the triglyceride level to $30.30 \%, 33.84$ and $37.43 \%$, respectively. The findings indicated a decline of triglycerides in a dose dependent manner. They observed effect of diet containing bitter gourd on triglyceride level during study period of 90 days. They obtained blood samples at every 15 days interval and observed continuous reduction in triglycerides compared to control group. Recently,

\section{Liver function test}

The reduction in ALP, ALT and AST level was recorded after feeding of diet containing bitter gourd compared to control groups. Serum creatinine and urea concentration was also remained in normal ranges due to feeding of bitter gourd in diet. The current data is comparable to the earlier investigations of Hossain et al. [27] confirmed a reduction in serum ALP, ALT and AST of rats treated with bitter gourd extract. In another study noted that bitter gourd is helpful in reducing the amount of ALT and AST. Moreover, Sathishsekar and Subramamian [32] also reported hepato-protective role of bitter gourd. The present data was comparable with the findings of Nagy et al. [33] showing decline in serum creatinine and urea level after bitter gourd administration.

\section{Effect on different organs}

Means for weight of different organs (Table 5) depicted non-significant impact of diet on various organs except for kidney and liver weight that were found higher in diabetic control rat as compared to rats fed with bitter gourd supplemented food. Liver weight was also noted slightly higher in control groups of hypercholesterolemic rats. Platel et al. [34] confirms the current results showed bitter gourd had no adverse effect on major organs of the body. A considerable elevation in kidney weight of diabetic rats might be due to hyperplasia and hypertrophy of tubular and mesangial cells of the kidney [35]. Treating the diabetic rats with bitter gourd caused a decrease in the weight of kidney and liver up to normal ranges.

\section{Discussions}

The findings of Jafri et al. [36] are in harmony with the current study, they reported substantial decrease in glucose of hyperglycemic rats after consuming bitter gourd powder. Singh and Gupta [37] also confirmed antihyperglycemic property of this plant in diabetic condition in both animals as well as in humans. Virdi et al. [38] also observed antihyperglycemic property of bitter gourd. In another study, Jayasooriya et al. [31] observed effects of bitter gourd powder in cholesterol free and cholesterol enriched diets fed rats and noted that there was a continuous decline in glucose level in groups of rat fed with cholesterol free diet while no significant influence was noted in rats fed with cholesterol enriched diets. Clouatre et al. [39] revealed reduction in blood glucose level by giving bitter gourd extracts at $50 \mathrm{mg} / \mathrm{kg}$ of body weight in normal rats.

The results for insulin in current study are in accordance with Mohammady et al. [40] noted significant increase in insulin in diabetic rats treated with bitter gourd as compared to diabetic control group. Similarly, Fernandes et al. [41] observed positive effect of bitter gourd extract on serum insulin level. The increase in insulin level in the diabetic rats after giving diet supplemented with bitter gourd might be due to recovery of beta cells of Langerhans $[37,41]$. Other studies indicated that addition of bitter gourd in diet enhance the number of beta cells [40]. However, researchers reported that bitter gourd did not involve in restoring of these cells rather it enhance the activity of beta cells.

The current investigation has shown bitter gourd effectiveness against cholesterol synthesis which is in accordance with the work of Jayasooria et al. [31] who used freeze-dried powder of bitter gourd to note its 
Table 5 Means for organ weight in different studies

\begin{tabular}{|c|c|c|c|c|c|c|c|c|}
\hline \multirow[t]{2}{*}{ Organs } & \multirow[t]{2}{*}{ Studies } & \multicolumn{7}{|c|}{ Group of rats fed with different diets } \\
\hline & & $D_{0}$ & $D_{1}$ & $\mathrm{D}_{2}$ & $D_{3}$ & $D_{4}$ & $D_{5}$ & $D_{6}$ \\
\hline \multirow[t]{3}{*}{ Heart } & Study I & $0.95 \pm 0.03$ & $0.93 \pm 0.02$ & $0.93 \pm 0.02$ & $0.92 \pm 0.02$ & $0.91 \pm 0.03$ & $0.92 \pm 0.02$ & $0.90 \pm 0.03$ \\
\hline & Study II & $0.95 \pm 0.02$ & $0.94 \pm 0.01$ & $0.93 \pm 0.02$ & $0.93 \pm 0.01$ & $0.92 \pm 0.01$ & $0.93 \pm 0.03$ & $0.92 \pm 0.02$ \\
\hline & Study III & $0.95 \pm 0.03$ & $0.95 \pm 0.01$ & $0.93 \pm 0.01$ & $0.94 \pm 0.02$ & $0.93 \pm 0.01$ & $0.93 \pm 0.03$ & $0.93 \pm 0.03$ \\
\hline \multirow[t]{3}{*}{ Lung } & Study I & $1.59 \pm 0.06$ & $1.60 \pm 0.06$ & $1.62 \pm 0.09$ & $1.57 \pm 0.11$ & $1.56 \pm 0.07$ & $1.60 \pm 0.11$ & $1.60 \pm 0.02$ \\
\hline & Study II & $1.59 \pm 0.03$ & $1.62 \pm 0.05$ & $1.62 \pm 0.04$ & $1.58 \pm 0.09$ & $1.63 \pm 0.03$ & $1.58 \pm 0.09$ & $1.59 \pm 0.06$ \\
\hline & Study III & $1.61 \pm 0.08$ & $1.63 \pm 0.04$ & $1.62 \pm 0.07$ & $1.60 \pm 0.08$ & $1.65 \pm 0.04$ & $1.61 \pm 0.06$ & $1.61 \pm 0.03$ \\
\hline \multirow[t]{3}{*}{ kidney } & Study I & $1.94 \pm 0.02$ & $1.90 \pm 0.03$ & $1.88 \pm 0.03$ & $1.89 \pm 0.07$ & $1.87 \pm 0.05$ & $1.89 \pm 0.07$ & $1.88 \pm 0.04$ \\
\hline & Study II & $2.01 \pm 0.07$ & $1.91 \pm 0.04$ & $1.87 \pm 0.04$ & $1.90 \pm 0.06$ & $1.88 \pm 0.04$ & $1.89 \pm 0.03$ & $1.87 \pm 0.05$ \\
\hline & Study III & $1.96 \pm 0.04$ & $1.91 \pm 0.04$ & $1.89 \pm 0.05$ & $1.90 \pm 0.06$ & $1.88 \pm 0.03$ & $1.90 \pm 0.03$ & $1.90 \pm 0.06$ \\
\hline \multirow[t]{3}{*}{ Liver } & Study I & $6.72 \pm 0.27$ & $6.60 \pm 0.10$ & $6.55 \pm 0.22$ & $6.59 \pm 0.23$ & $6.51 \pm 0.20$ & $6.56 \pm 0.12$ & $6.53 \pm 0.19$ \\
\hline & Study II & $7.23 \pm 0.37$ & $6.69 \pm 0.24$ & $6.66 \pm 0.12$ & $6.69 \pm 0.10$ & $6.60 \pm 0.14$ & $6.63 \pm 0.17$ & $6.59 \pm 0.24$ \\
\hline & Study III & $7.58 \pm 0.21$ & $7.04 \pm 0.20$ & $6.85 \pm 0.16$ & $6.96 \pm 0.17$ & $6.84 \pm 0.09$ & $6.93 \pm 0.26$ & $6.77 \pm 0.07$ \\
\hline \multirow[t]{3}{*}{ Pancreas } & Study I & $2.02 \pm 0.11$ & $2.03 \pm 0.20$ & $2.05 \pm 0.11$ & $2.02 \pm 0.03$ & $2.02 \pm 0.13$ & $2.04 \pm 0.06$ & $2.03 \pm 0.07$ \\
\hline & Study II & $1.87 \pm 0.06$ & $2.01 \pm 0.09$ & $2.01 \pm 0.07$ & $2.03 \pm 0.04$ & $2.04 \pm 0.10$ & $2.04 \pm 0.05$ & $2.05 \pm 0.07$ \\
\hline & Study III & $1.95 \pm 0.11$ & $2.04 \pm 0.10$ & $2.02 \pm 0.03$ & $2.04 \pm 0.04$ & $2.01 \pm 0.13$ & $2.03 \pm 0.04$ & $2.02 \pm 0.03$ \\
\hline \multirow[t]{3}{*}{ Spleen } & Study I & $0.49 \pm 0.04$ & $0.51 \pm 0.06$ & $0.49 \pm 0.02$ & $0.49 \pm 0.01$ & $0.48 \pm 0.03$ & $0.49 \pm 0.05$ & $0.48 \pm 0.03$ \\
\hline & Study II & $0.41 \pm 0.04$ & $0.51 \pm 0.04$ & $0.50 \pm 0.04$ & $0.50 \pm 0.05$ & $0.49 \pm 0.04$ & $0.50 \pm 0.01$ & $0.48 \pm 0.03$ \\
\hline & Study III & $0.48 \pm 0.03$ & $0.51 \pm 0.05$ & $0.51 \pm 0.02$ & $0.51 \pm 0.06$ & $0.50 \pm 0.03$ & $0.49 \pm 0.05$ & $0.49 \pm 0.02$ \\
\hline
\end{tabular}

effect on lipid parameters in rats fed with diet supplemented with and without cholesterol. They observed 32.0 and $22.4 \%$ decline in total cholesterol level in the absence and presence of dietary cholesterol, respectively. Abas et al. [42] revealed that total cholesterol was significant increase in diabetic rats compared to control. Consumption of bitter gourd for 28 days showed significant reduction in cholesterol compared to diabetic control group. In an experiment on Wistar rats, decrease in cholesterol was noticed after consuming bitter gourd fruit extract [41]. Similarly, Bano et al. [30] observed significant reduction (21\%) in cholesterol after oral administration of aqueous extract of bitter gourd for a period of 5 weeks. Later, in an antidiabetic study by Wehash et al. (2012) on male Sprague-Dawley rats indicated lipid lowering effect of bitter gourd. Hossain et al. (2012) investigated antihyperglycemic and antihyperlipidemic effect of aqueous extract of bitter gourd at daily dose of 250, 500 and $750 \mathrm{mg} / \mathrm{kg}$ body weight. They observed $12.88,14.44$ and $17.21 \%$ reduction in serum cholesterol, respectively.

Wehash et al. [43] observed significant reduction in LDL level from 141.51 to $31.18 \mathrm{mg} / \mathrm{dL}$ in diabetic group fed with control diet and bitter gourd supplemented diet, respectively.another researcher noted increase in LDL in STZ induced diabetic control and decline in all the experimental groups at the end of 28 day study period. Similarly, Chaturvedi et al. [44] also found reduction in amount of low density lipoproteins in blood by administering bitter gourd extracts. The lowering of LDL by consuming bitter gourd in diet might be due to secretion of Apolipoprotein-B by the liver.

\section{Conclusions}

It is evident from the present research findings that conspicuous from the contemporary endeavor that among various parts of bitter gourd, whole fruit part in a dose of $300 \mathrm{mg} / \mathrm{kg}$ body weight found to be suitable in lowering blood glucose level, increasing serum insulin level, reduction in cholesterol, increase in HDL and minimize the amount of low density lipoprotein and triglycerides. Moreover, level of ALP, ALT, AST, serum creatinine and urea reduced to normal ranges by consumption of bitter gourd. Being veracious and concise, it is executed that bitter gourd be endowed with vivid approaching to improve the effect of oxidative stress, thus stopping the chain reactions implicated in the onset of chronic diseases. The outcomes of current project found bitter gourd most effective against obesity and chronic aberrations such as hyperglycemia and hyperlipidemia. It is vigorously suggested to devise diet based modules to use bitter gourd against lifestyle related disorders.

\section{Acknowledgements}

The authors are highly obliged to the research facilities of the Institute of Home and Food Sciences, Government College University Faisalabad (GCUF) and IT Department, Higher Education Commission (HEC, Islamabad) for access to journals, books and valuable database. 


\section{Funding}

The authors are grateful to Higher Education Commission (HEC), Government of Pakistan for their financial support to carry out the present research.

\section{Availability of data and materials}

The dataset supporting the conclusions of this article is included within the article.

\section{Authors' contributions}

The contribution of each author for this manuscript was as follows; M \& FS designed the experimental plan of this study as well as conducted the analysis. $\mathrm{M}$ and FS and MSA drafted the manuscript. MN, MTN helped to improve the manuscript and especially MUA provided help in reviewing the paper. It is also confirmed that all the authors read and approved the final manuscript.

\section{Ethics approval and consent to participate}

Not Applicable

\section{Consent for publication}

\section{Not Applicable}

\section{Competing interests}

The authors declare that they have no competing interests.

\section{Publisher's Note}

Springer Nature remains neutral with regard to jurisdictional claims in published maps and institutional affiliations.

Received: 15 August 2017 Accepted: 30 October 2017

Published online: 10 November 2017

\section{References}

1. Mugisha JO, Schatz EJ, Randell M, Kuteesa M, Kowal P, Negin J, Seeley J. Chronic disease risk factors and disability in adults aged 50 and above living with and without HIV: findings from the wellbeing of older people study in Uganda. Glob Health Action. 2016;9:31098.

2. Dayoub E, Jena AB. Chronic disease prevalence and healthy lifestyle behaviors among US health care professionals. Mayo Clin Proc. 2015;90(12):1659.

3. Shaw JE, Sicree RA, Zimmet PZ. Global estimates of the prevalence of diabetes for 2010 and 2030. Diabetes Res Clin Prac. 2010;87(1):4

4. Abid R, Mahmood R, Kumar HSS. Hypolipidemic and antioxidant effects of ethanol extract of Cassia Fistula fruit in hyperlipidemic mice. Pharm Biol. 2016;1:8.

5. Mundal L, Retterstl K. A systematic review of current studies in patients with familial hypercholesterolemia by use of national familial hypercholesterolemia registries. Curr Opin Lipidol. 2016;27(4):388-97.

6. Raman BV, Krishna NV, Rao NB, Saradhi PM, Rao BMV. Plants with antidiabetic activities and their medicinal values. Int Res J Pharm. 2012;3(3):11.

7. Bhushan MS, Rao CHV, Ojha SK, Vijayakumar M, Verma A. An analytical review of plants for anti-diabetic activity with their phytoconstituent and mechanism of action. Int J Pha Sci Res. 2010;1(1):29.

8. Taylor L. Herbal secrets of the rainforest. In: Texas A, editor. Bitter melon (Momordica Charantia). 2nd ed. USA: Sage Press; 2002. p. 1.

9. Dandawate PR, Subramaniam D, Padhye SB, Anan S. Bitter melon: a panacea for inflammation and cancer. Chin J Nat Med. 2016;14:81.

10. Kubola J, Siriamornpun S. Phenolic contents and antioxidant activities of bitter gourd (momordica charantia I.) leaf stem and fruit fraction extracts in vitro. Food Chem. 2008;110(4):881.

11. Basch E, Gabardi S, Ulbricht C. Bitter melon (Momordica charantia): a review of efficacy and safety. Ame J Hea-Sys Pha. 2003;60:356.

12. Rahman IU, Khan RU, Rahman KU, Bashir M. Lower hypoglycemic but higher antiatherogenic effects of bitter melon than glibenclamide in type 2 diabetic patients. Nutr J. 2015;14:13.

13. Tayyab F, Lal SS. Antidiabetic hypolipidemic and antioxidant activity of Momordica charantia on type-II diabetic patient in Allahabad India. Int J Pharma Bio Sci. 2013;4:932.

14. Tayyab F, Lal SS, Mishra M, Kumar U. A review: medicinal plants and its impact on diabetes. World J Pharma Res. 2012;1(4):1019.

15. Chen PH, Chen GC, Yang MF, Hsieh CH, Chuang SH. Bitter melon seed oil-attenuated body fat accumulation in diet-induced obese mice is associated with CAMP-dependent protein kinase activation and cell death in white adipose tissue. J Nut. 2012;142:1197.
16. Katz A, Nambi SS, Mather K, Baron AD, Follmann DA, Sullivan G, Quon MJ. Quantitative insulin sensitivity check index: a simple accurate method for assessing insulin sensitivity in humans. J Cli End Met. 2000;85:2402.

17. Ahn J, Choi W, Kim S, Ha T. Anti-diabetic effect of watermelon (Citrullus vulgaris Schrad) on streptozotocin-induced diabetic mice. Food Sci Bio. 2011;20(1):251.

18. Kim Jl, Paik JK, Kim OY, Park HW, Lee JH, Jang Y, Lee JH. Effects of lycopene supplementation on oxidative stress and markers of endothelial function in healthy men. Atherosclerosis. 2011;215:189.

19. Alshatwi AA, Al-Obaaid MA, Al-Sedairy SA, Al-Assaf AH, Zhang J, Lei KY. Tomato powder is more protective than lycopene supplement against lipid peroxidation in rats. J Nut Res. 2010;30:66.

20. Basuny AM, Gaafar AM, Arafat SM. Tomato lycopene is a natural antioxidant and can alleviate hypercholesterolemia. Afr J Bio. 2009;8(23):6627.

21. Thomas L. Clinical laboratory diagnostics. 1st ed. Frankfurt: TH-Books Verlagsgesellschaft; 1998. p. 241.

22. Jacobs DS, DeMott WR, Grady HJ, Horvat RT, Huestis DW, Kasten BL. Laboratory test handbook 4th Ed. Hudson (Cleveland): Lexi-comp Inc; 1996.

23. Steel RGD, Torrie JH, Dickey D. Principles and procedures of statistics: a biometrical approach 3rd Ed. New York: McGraw Hill Book Co. Inc; 1997.

24. Klomann SD, Mueller AS, Pallauf J, Krawinkel MB. Antidiabetic effects of bitter gourd extracts in insulin-resistant db/db mice. Br J Nutr. 2010;104: 1613.

25. Shetty AK, Kumar GS, Sambaiah K, Salimath PV. Effect of bitter gourd (Momordica charantia) on glycaemic status in streptozotocin induced diabetic rats. Plant Food Hum Nut. 2005;60:109.

26. Parmar K, Patel S, Patel J, Patel B, Patel MB. Effects of bittergourd (Momordica charantia) fruit juice on glucose tolerance and lipid profile in type-II diabetic rats. Int J Drug Dev Res. 2011;3(2):139-46.

27. Hossain MA, Mostofa M, Debnath D, Alam AKMR, Yasmin Z, Moitry NF. Antihyperglycemic and antihyperlipidemic of Karala (Momordica charantia) fruits in streptozotocin induced diabetic rats. J Env Sci Nat Res. 2012;5(1):29.

28. Tymoczko JL, Stryer BT, Stryer L, Berg JM. Biochemistry. San Francisco: W.H. Freeman; 2002. p. 726

29. Temitope AG, Sheriff OL, Azeezat YF, Taofik A, Fatimah Al. Cardioprotective properties of Momordica charantia in albino rats. Afri J Sci Res. 2013:11(1):600.

30. Bano F, Akthar N, Naz H. Effect of the aqueous extract of Momordica charantia on body weight of rats. J Bas App Sci. 2011;7(1):1.

31. Jayasooriya AP, Sakono M, Yukizaki C, Kawano M, Yamamoto K, Fukuda N. Effects of Momordica charantia powder on serum glucose levels and various lipid parameters in rats fed with cholesterol-free and cholesterol-enriched diets. J Eth. 2000;72(1-2):331.

32. Sathishsekar D, Subramanian S. Antioxidant properties of Momordica charantia (bitter gourd) seeds on Streptozotocin induced diabetic rats. Asia Pac J Clin Nut. 2005;14(2):153-8.

33. Nagy MA, Bastawy MA, Abdel-Hamid NM. Effects of Momordica charantia on Streptozotocin-induced diabetes in rats: role of insulin oxidative stress and nitric oxide. J Health Sci. 2012;2(2):8.

34. Platel K, Shurpalekar KS, Srinivasan K. Influence of bitter gourd (Momordica charantia) on growth and blood constituents in albino rats. Nahrung. 1993; 37(2):156-60.

35. Bulut HE, Onarlioglu B, Kaloglu C, Ozdemir O, Ayan S. Effects of experimental diabetes an insulin treatment on rabbit renal morphology: a quantitative and qualitative study. Tur J Med Sci. 2001;31:209.

36. Jafri SA, Ismail MS, Zaman G. Effect of Momordica charantia (karela) in alloxan induced diabetic rats. Pak J Sci. 2009;61(4):220.

37. Singh N, Gupta M. Regeneration of beta cells in islets of Langerhans of pancreas of alloxan diabetic rats by acetone extract of Momordica charantia (Linn.) (bitter gourd) fruits. Indian J Exp Bio. 2007;45(12):1055-62.

38. Virdi J, Sivakami S, Shahani S, Suthar AC, Banavalikar MM, Biyani MK. Antihyperglycemic effects of three extracts from Momordica charantia. J Ethnopharmacol. 2003:88:107.

39. Clouatre DL, Rao SN, Preuss HG. Bitter melon extracts in diabetic and normal rats favorably influence blood glucose and blood pressure regulation. J Med Food. 2011;14(12):1496.

40. Mohammady I, Elattar S, Mohammed S, Ewais M. An evaluation of anti-diabetic and anti-lipidemic properties of Momordica charantia (bitter melon) fruit extract in experimentally induced diabetes. Life Sci J. 2012;9(2):363.

41. Fernandes NP, Lagishetty CV, Panda VS, Naik SR. An experimental evaluation of the antidiabetic and antilipidemic properties of a standardized Momordica charantia fruit extract. BMC Com Alt Med. 2007;7:29. 
42. Abas R, Das S, Thent ZC. Momordica Charantia fruit extract improve subcellular changes in cardiovascular tissues of diabetic rats. J Med Bio. 2015;4:357.

43. Wehash FE, Abo-Ghanema I, Saleh RM. Some physiological effects of Momordica charantia and Trigonella foenum-graecum extracts in diabetic rats as compared with Cidophage ${ }^{\circledR}$ world. Acad Sci Eng Tech. 2012;64:1206

44. Chaturvedi P, George S, Milinganyo M, Tripathi YB. Effect of Momordica charantia on lipid profile and oral glucose tolerance in diabetic rats. Phy Res. 2004;18(11):954.

Submit your next manuscript to BioMed Central and we will help you at every step:

- We accept pre-submission inquiries

- Our selector tool helps you to find the most relevant journal

- We provide round the clock customer support

- Convenient online submission

- Thorough peer review

- Inclusion in PubMed and all major indexing services

- Maximum visibility for your research

Submit your manuscript at www.biomedcentral.com/submit
Biomed Central 